\title{
COMPLEMENT [FIXATION WITH ANTIGENS PREPARED FROM BLUETONGUE VIRUS-INFECTED MOUSE BRAINS
}

\author{
By A. KIPPS \\ The C.S.I.R. and U.C.T. Virus Research Unit, Department of Pathology, \\ University of Cape Town
}

\section{INTRODUCTION}

Little was known about the antigenic structure of the bluetongue virus until Neitz (1948) established the existence of a multiplicity of strains which could be distinguished from one another by cross-immunity tests in sheep. Since then Alexander \& Haig (1951) have contributed their important observations on the alteration of behaviour of the virus during passage from fertile eggs to sheep, and van den Ende, Linder \& Kaschula (1954) demonstrated in one strain the presence of a 'soluble' antigen by complement fixation.

It was realized that the bluetongue virus was admirably suited to a detailed study of the antigenic structure by techniques which have been applied to other viruses. In particular, it was thought that cross complement-fixation tests would yield useful information about the structure of the viruses, their suitability for incorporation in polyvalent vaccines against the disease in sheep, and about the serological specificity of soluble antigens present in the brains of suckling mice infected with different bluetongue viruses.

This paper records some of the observations made on the use of complementfixation tests with the various strains of bluetongue virus and immune sera produced in adult mice.

\section{MATERIALS AND METHODS}

At the time these investigations were started there were six strains of bluetongue available in this laboratory. These strains, which had been received from Dr R. A. Alexander of the Onderstepoort Laboratories in Pretoria, were selected because they showed differences in neutralization tests. Four of them, 'Theiler', 'Cyprus', 'Bekker' and 'Jansen', were egg-adapted when received, but the remaining two strains, 'Mimosa Park' and 'Estantia', had been adapted directly from infected sheep blood to suckling mouse brains. The four egg-adapted strains were adapted to suckling mouse brains without difficulty, and after several passages they were so well established that the brains of baby mice infected with any one of them could regularly be harvested on the third day after inoculation when the mice were almost invariably dead or very ill. The most constant results were obtained with 2-4-day-old mice, even although mice older than 4 days but younger than 13 days were susceptible to intracerebral inoculation of suckling mouse-adapted bluetongue virus (van den Ende et al. 1954). 


\section{Preparation of immune sera}

From the work of van den Ende et al. (1954) it was known that adult mice receiving repeated intraperitoneal injections of infected suckling mouse brains provide a suitable bluetongue immune serum for complement-fixation tests. Since the immune sera were required to be highly specific it was thought advisable to give a short course of injections rather than a long one, which might achieve higher titres but with a loss of specificity.

To prepare a suspension for the immunization of mice, fifty infected suckling mouse brains were emulsified in $100 \mathrm{ml}$. of sterile saline, lightly centrifuged and dispensed in four $25 \mathrm{ml}$. screw-capped bottles. To each bottle was added an appropriate amount of penicillin and streptomycin, and the suspensions were stored in the ordinary refrigerator at $4^{\circ} \mathrm{C}$. until required.

Groups of fifty adult mice received $0.5 \mathrm{ml}$. amounts of this saline suspension by intraperitoneal injection every fourth day until four injections had been given. The mice were bled from the heart 10-12 days after the last injection.

The blood was allowed to clot and to remain overnight at $4^{\circ} \mathrm{C}$. The following morning the serum was collected and inactivated at $56^{\circ} \mathrm{C}$. for $50 \mathrm{~min}$. The sera were stored at $-20^{\circ} \mathrm{C}$.

\section{Neutralization tests}

Observations were recorded on the degree of protection provided by the six immune sera against each of the six strains of virus.

For these tests the immune sera were diluted $1 / 10$, Seitz filtered and stored at $-20^{\circ} \mathrm{C}$., and maintained under identical conditions until the whole series of tests were completed.

Each strain of bluetongue virus was titrated in turn in 2-4-day-old suckling mice and stored in the $4^{\circ} \mathrm{C}$. refrigerator until the $\mathrm{LD}_{50}$ could be calculated by the method of Reed \& Muench (1938).

Serum-virus mixtures were prepared by adding $20 \mathrm{LD}_{50}$ of the virus suspension to equal volumes of four dilutions of each of the six immune sera, giving a final dilution of virus equivalent to $10 \mathrm{LD}_{50}$.

After $30 \mathrm{~min}$. at room temperature and $30 \mathrm{~min}$. at $4^{\circ} \mathrm{C} ., 0.02 \mathrm{ml}$. of each mixture was inoculated intracerebrally into 2-4-day-old suckling mice using a different syringe for each sample. The mice were randomized before inoculation so that 6-8 young were left in the care of each mother. Three control litters were inoculated with 1,10 and $20 \mathrm{LD}_{50}$ respectively.

The litters were examined daily for 10 days.

\section{Demonstration of the soluble antigen}

Complement-fixing components separable from the infectious virus units were demonstrated in crude saline suspensions, and in acetone and ether extracts of infected suckling mouse brains subjected to ultracentrifugation.

In a typical experiment a $40 \%$ suspension was centrifuged at 2000 r.p.m. for $\frac{1}{2} \mathrm{hr}$. to remove large particles and then at 30,000 r.p.m. for $1 \mathrm{hr}$. in a Spinco model 
L centrifuge, which caused an appreciable sedimentation of the virus, as evidenced by titration of samples collected at $1 \mathrm{~cm}$. levels down the centrifuge tube according to the method of Polson et al. (Polson \& Linder, 1953; Polson \& Madsen, 1954).

After such preliminary centrifugation the supernatant fluid was re-centrifuged at 30,000 r.p.m. for $180 \mathrm{~min}$. and samples were collected with a very finely drawn Pasteur pipette from successive $0.5 \mathrm{~cm}$. levels down the tube. Each of these samples was then tested for its complement-fixing power, after which successive pairs of samples were pooled and titrated in suckling mice.

\section{Preparation of antigen for complement-fixation tests}

Suckling mice aged 2-4 days were given intracerebral inocula of $0.02 \mathrm{ml}$. of a $2 \%$ emulsion of virus-infected brains. The mice were examined daily, and when the first symptoms appeared-almost invariably $48 \mathrm{hr}$. after inoculation-the mothers were removed from the litters to avoid cannibalism, which otherwise invariably occurred and resulted in heavy losses of material.

The following morning the sick were killed with ether vapour. The brains were harvested under sterile conditions, both from mice that had died overnight and from those killed, and were stored in $5 \mathrm{ml}$. screw-capped bottles in solid $\mathrm{CO}_{2}$, until enough had been collected to proceed with the further preparation of antigen. Slow freezing in the $-20^{\circ} \mathrm{C}$. deep-freeze was found to be a very dangerous procedure which, as pointed out by Alexander (1947), might completely inactivate the virus.

For the initial cross complement-fixation tests one large batch of antigen was prepared from each strain of bluetongue virus by the method of Casals (1949). In this method infected brains were subjected to repeated preliminary extractions with chilled ether and acetone. The final saline extract was ampouled in $1.5 \mathrm{ml}$. amounts and stored at $-76^{\circ} \mathrm{C}$. This material retained its complement-fixing power for at least 15 months.

For later experiments antigens were prepared by making simple $10 \%$ saline emulsions of infected suckling mouse brains followed by centrifugation at 2000 r.p.m. for $1 \mathrm{hr}$. to remove gross particulate matter.

\section{Complement and sensitized cells}

Only fresh guinea-pig sera with an adequate titre of complement $(1 / 120)$ were used. Dilutions were made in chilled diluent to give a range from $1 / 3 \cdot 2$ to $1 / 316$ in 1.58-fold (autolog 0.2) steps. The diluent was one similar to that of Mayer, Osler, Bier \& Heidelberger (1946) and as modified by Fulton \& Dumbell (1949).

Sheep cells stored in Alsever's solution were washed three times in saline and diluted to make a $2 \%$ suspension. (The $0 \cdot 2 \%$ suspension recorded by Fulton \& Dumbell was found unsuitable.) The cells were sensitized with stock haemolysin at a dilution of $1 / 500$, which is equivalent to 10 M.H.D. per unit volume, and allowed to remain at $37^{\circ} \mathrm{C}$. for $1 \mathrm{hr}$. before use. 


\section{Complement-fixation tests}

For serological comparison of the six strains of bluetongue virus the standard technique for cross complement-fixation tests designed by Fulton \& Dumbell (1949) was used. Slight modifications of the original method were introduced in view of the reports of van den Ende, Turner, Selzer \& Naude (1953) and Kraft \& Melnick (1950), and in the light of our experience gained in experiments with the bluetongue virus.

The tests were carried out on Perspex sheets 12 in. square and $\frac{1}{8}$ in. thick. Each test was a two-dimensional 'chess-board' experiment with variation of the complement and of the antigen or the serum. It was possible to titrate complement and to determine the anticomplementary effect of either antigen or serum on each sheet.

'50-dropper' pipettes were used throughout for delivering $0.2 \mathrm{ml}$. amounts of the various reagents. After the appropriate reagents had been distributed over the sheets, as described by Fulton \& Dumbell, they were held at $4^{\circ} \mathrm{C}$. for $18-20 \mathrm{hr}$. Fully sensitized cells were then added and the sheets kept at $37^{\circ} \mathrm{C}$. for $2 \mathrm{hr}$.

\section{Standardization of the antigens}

Each antigen was standardized against its homologous antiserum by recording the amount of complement fixed by varying dilutions of the antigen in the presence of an excess of antibody, i.e. 1/2 dilution of homologous immune serum.

The dilution of antigen which fixed a standard amount of complement, in our experiments $\mathrm{I} \cdot 0 \mathrm{~mm} .^{3}$, was read as the 'standard dilution' of the antigen. It was found that all six acetone and ether-extracted antigens fixed $1.0 \mathrm{~mm} .^{3}$ of complement over a very narrow range of dilutions, in fact it was possible to use a dilution of $1 / 6$ as the standard dilution for all six strains of bluetongue virus.

In the case of the crude saline extracts (prepared at a different time) it was found that four of the antigens had to be diluted $1 / 8$ while one required dilution to $1 / 16$ (Cyprus) and the sixth to $1 / 48$ (Jansen).

Preliminary observations showed that normal mouse serum fixed appreciable amounts of complement. The addition of standard amounts of antigen to the various dilutions of normal mouse serum showed, however, that there was no greater fixation of complement. Complement titrated in the presence of standard amounts of antigen in fact frequently gave a slightly higher reading than complement titrated alone. This protective effect of the antigen has been observed by Casals (1947) and Kerr (1952). The antigen in standard dilution was not anticomplementary.

Corrections were made for the non-specific fixation of complement by deducting from the total complement fixed, the amounts fixed by corresponding dilutions of normal mouse serum. The remainder represented the 'specific fixation'. This was expressed in log units of complement, taking as the unit the amount of complement causing $50 \%$ haemolysis of sensitized cells in the presence of antigen.

The log units of complement were plotted against serum dilutions, and the areas thus described were estimated in planimeter units. Comparison of the areas 
was made by attributing to the homologous reactions the value of unity and expressing the heterologous reactions proportionately according to the suggestion of Fulton \& Dumbell.

\section{RESULTS}

From the results of the neutralization tests given in Table 1, it can be seen that important differences exist between the strains. The Cyprus, Jansen and Bekker varieties appear to be closely related and can for convenience be grouped together. Mimosa Park shows slight differences from this group, but Theiler and Estantia appear to be markedly different from them and from each other.

Table 1. Neutralization tests with six strains of bluetongue virus with homologous and heterologous sera

\begin{tabular}{lcccccc} 
& \multicolumn{7}{c}{} & Sera \\
Viruses & Cyp. & Th. & M.P. & Est. & Jan. & Bek. \\
Cyp. & ++++ & + & +++ & +++ & +++ & ++++ \\
Th. & 0 & ++++ & + & 0 & 0 & 0 \\
M.P. & ++ & + & ++ & + & ++ & ++ \\
Est. & + & + & 0 & ++++ & + & ++ \\
Jan. & +++ & 0 & ++ & 0 & ++++ & ++++ \\
Bek. & ++++ & + & ++ & +++ & ++++ & ++++
\end{tabular}

$++++=$ protection equivalent to that with homologous serum.

$+++=$ protection equivalent to approximately $75 \%$ of that of homologous serum.

$++=$ protection equivalent to approximately $50 \%$ of that of homologous serum.

$+=$ protection equivalent to approximately $25 \%$ of that of homologous serum.

$0=$ no protection with highest concentration of serum used (1/10).

Table 2. Comparison of six strains of bluetongue virus by complement-fixation tests with homologous and heterologous sera

Antigens as crude saline extracts.

'Area' of fixation with homologous reagents $=1 \cdot 0$ (see Fig. 1).

Antigens

$\begin{array}{lclcccc} & & & & & \\ \text { Sera } & \text { Cyp. } & \text { Th. } & \text { M.P. } & \text { Est. } & \text { Jan. } & \text { Bek. } \\ \text { Cyp. } & 1 \cdot 0 & 1 \cdot 0 & 0 & 0 & 1 \cdot 0 & 0 \cdot 8 \\ \text { Th. } & 0 \cdot 7 & 1 \cdot 0 & 0.3 & 0 & 0 \cdot 6 & 0 \cdot 9 \\ \text { M.P. } & 1 \cdot 1 & 1 \cdot 0 & 1 \cdot 0 & 0 & 1 \cdot 1 & 0 \cdot 6 \\ \text { Est. } & 0 \cdot 8 & 1 \cdot 0 & 0 \cdot 4 & 1 \cdot 0 & 1 \cdot 2 & 0 \cdot 8 \\ \text { Jan. } & 0 & 0 & 0 \cdot 1 & 0 & 1 \cdot 0 & 0 \cdot 1 \\ \text { Bek. } & 0.7 & 0.8 & 0.3 & 0 & 1 \cdot 2 & 1 \cdot 0\end{array}$

Comparison of the sera by complement fixation with crude saline extracts showed more marked overlapping between strains (Table 2, Fig. 1) than did the neutralization tests, whilst in tests made with acetone- and ether-extracted (Casals) antigens no significant differences could be observed (Table 3, Fig. 2).

The sedimentation of the bluetongue virus in crude saline suspensions of bluetongue-infected suckling mouse brains by ultracentrifugation for $1 \mathrm{hr}$. at 30,000 r.p.m. is shown in Fig. 3. Prolonged re-centrifugation of the supernatant fluid at 
Table 3. Comparison of two groups of four bluetongue viruses with homologous and heterologous sera

Antigens in acetone- and ether-extracted infected suckling mouse brains.

'Area' of fixation with homologous reagents $=1 \cdot 0$ (see Fig. 2).

Antigens

$\begin{array}{lcccc}\text { Sera } & \text { Bekker } & \text { Estantia } & \text { Cyprus } & \text { Jansen } \\ \text { Bekker } & 1 \cdot 0 & 1.0 & 0.6 & 1.0 \\ \text { Estantia } & 0.8 & \mathbf{1 . 0} & 0.8 & 0.9 \\ \text { Cyprus } & 1 \cdot 1 & \mathbf{0 . 8} & 1 \cdot 0 & \mathbf{1 . 0} \\ \text { Jansen } & 0.9 & \mathbf{0 . 9} & 0.9 & 1.0\end{array}$

$\begin{array}{lcccc}\text { Jansen } & 0.9 & 0.9 & 1.0 \\ \text { Sera } & \overbrace{\text { Bekker }} & \text { Estantia } & \text { Mimosa P. } & \text { Theiler } \\ \text { Bekker } & 1.0 & 0.9 & 0.9 & 0.8 \\ \text { Estantia } & 0.7 & 1 \cdot 0 & 0.7 & 0.8 \\ \text { Mimosa Park } & 1.0 & 0.8 & 1.0 & 0.8 \\ \text { Theiler } & 0.9 & 0.9 & 0.9 & 1.0\end{array}$
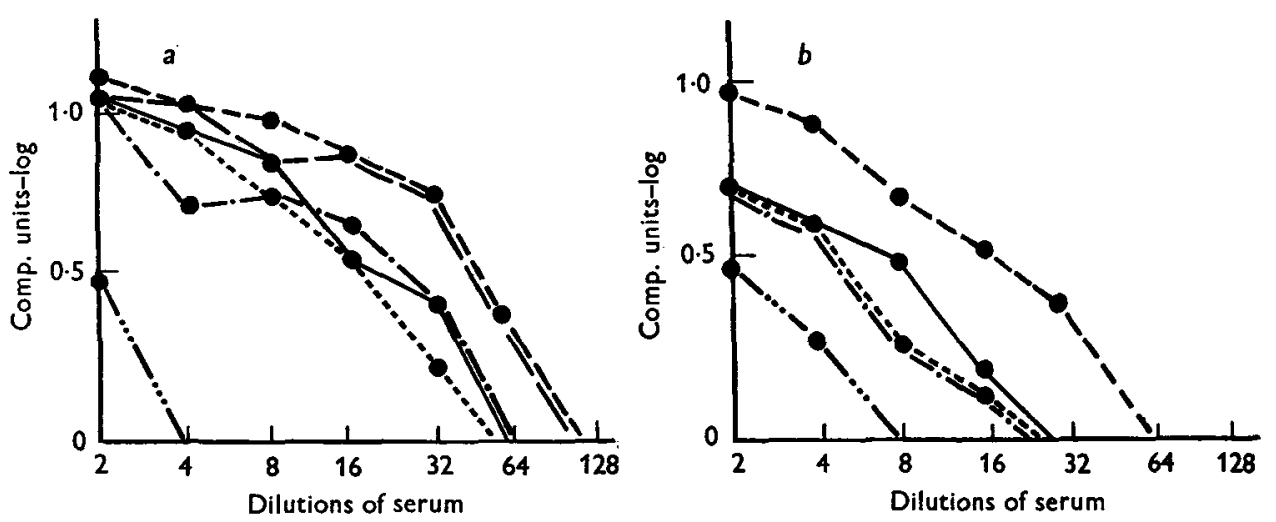

Fig. 1. a. Comparison of six strains of bluetongue virus in the presence of Cyprus immune serum. Antigens in the form of crude saline extracts. Index 1.0 represents 'area' of fixation with homologous antigen.

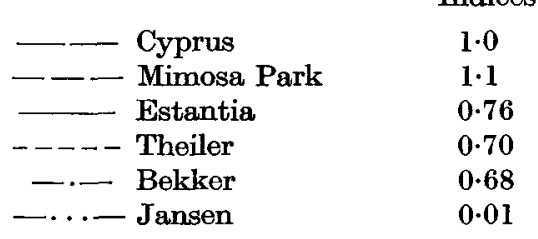

b. Comparison of six strains of bluetongue virus in the presence of Mimosa Park immune serum. Antigens in the form of crude saline extracts. Index 1.0 represents 'area' of fixation with homologous antigen.

\begin{tabular}{|c|c|}
\hline _- - Mimosa Park & $1 \cdot 0$ \\
\hline - Estantia & $0 \cdot 41$ \\
\hline - - - - Theiler & $0 \cdot 35$ \\
\hline —.- Bekker & $0 \cdot 34$ \\
\hline -... J Jansen & $0 \cdot 11$ \\
\hline Cyprus & $0 \cdot 0$ \\
\hline
\end{tabular}


30,000 r.p.m. for $3 \mathrm{hr}$. showed that the residual virus was almost completely sedimented, and even at the $5 \mathrm{~cm}$. level in the tube the amount of virus present was only about $1 / 10,000$ of that in the original suspension (Fig. 4). The supernatant fluid from such a re-centrifuged sample, however, contained appreciable amounts of complement-fixing antigen, consisting of particles of varying size (Fig. 5).
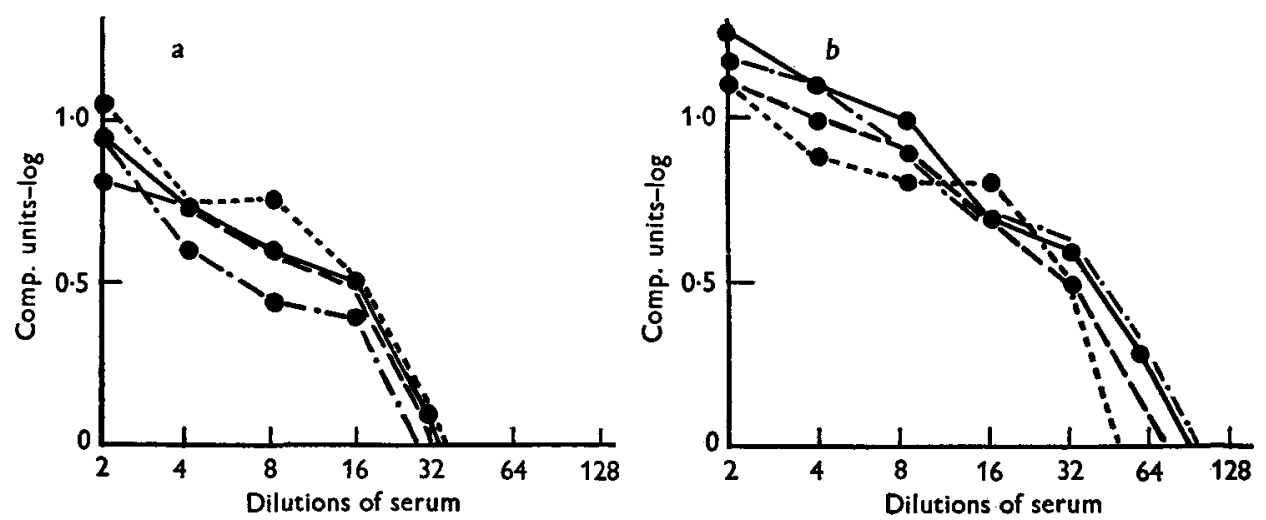

Fig. 2. a. Comparison of four strains of bluetongue virus in the presence of Cyprus immune serum. Antigens in the form of extracts from acetone- and ether-extracted brains. Index $I \cdot 0$ represents 'area' of fixation with homologous antigen.

\begin{tabular}{cc} 
& Indices \\
\hline- Cyprus & $1 \cdot 0$ \\
-- Bekker & $1 \cdot 1$ \\
- Jansen & 0.97 \\
.-- Estantia & 0.77
\end{tabular}

b. Comparison of four strains of bluetongue virus in the presence of Bekker immune serum. Antigens in the form of extracts from acetone- and ether-extracted brains. Index 1.0 represents 'area' of fixation with homologous antigen.

$\begin{array}{lc} & \text { Indices } \\ - \text { Bekker } & 1 \cdot 0 \\ - \text { Estantia } & 0.9 \\ - \text { - Mimosa Park } & 0.9 \\ ---- \text { Theiler } & 0.8\end{array}$

\section{DISCUSSION}

The difference between the strains observed in the complement-fixation tests with crude saline extracts may well depend upon unavoidable differences in the effectiveness of the extraction of the antigenic components from the suckling mouse brains. Others in this laboratory have found that the acetone- and ether-extraction method gives a more reliable and effective method for the extraction of soluble antigen.

We have obtained evidence that soluble antigen obtained from acetone- and ether-extracted brains is in the form of uniform small particles, whilst that in the crude saline extracts occurs in particles of varying size (Fig. 5), intermediate between the soluble antigen in the acetone- and ether-extracted material and virus particles themselves. This suggests that increasing complexity evidenced by increasing size 


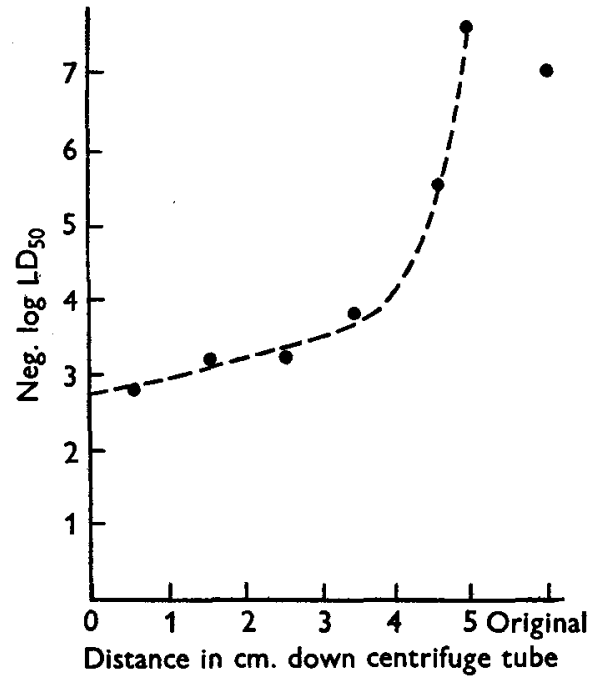

Fig. 3.

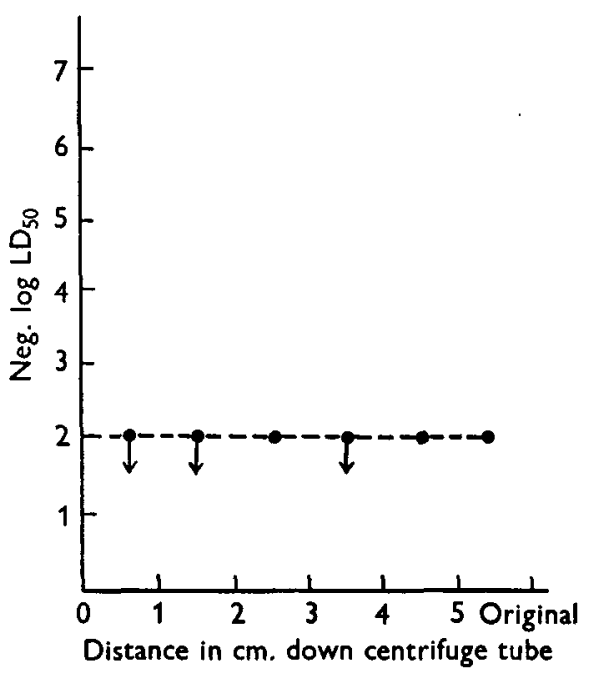

Fig. 4.

Fig. 3. Ultracentrifugation of saline extract of bluetongue-infected brains. Titres expressed in neg. $\log \mathrm{LD}_{50}$ of infective virus in samples taken at different levels in the centrifuge tube after centrifugation at 30,000 r.p.m. for $1 \mathrm{hr}$.

Fig. 4. Ultracentrifugation of saline extract of bluetongue-infected brains previously centrifuged at 30,000 r.p.m. for $1 \mathrm{hr}$. (see Fig. 3). Titration of bluetongue virus expressed in neg. $\log L D_{50}$ of infected virus in samples taken at different levels in the centrifuge after centrifugation at 30,000 r.p.m. for $3 \mathrm{hr}$.

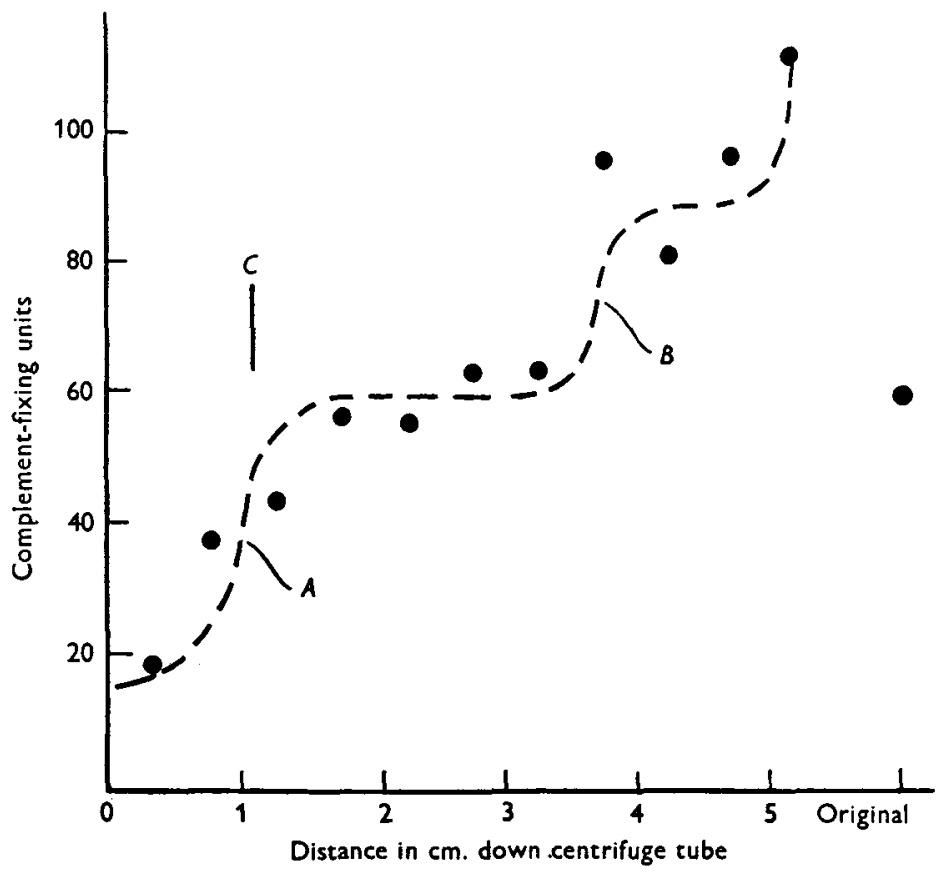

Fig. 5. Ultracentrifugation of saline emulsion of bluetongue-infected mouse brains previously centrifuged at 30,000 r.p.m. for $1 \mathrm{hr}$. Titration of complement-fixing antigens in samples taken at different levels in the centrifuge tube after centrifugation at 30,000 r.p.m. for $3 \mathrm{hr}$. (compare Fig. 4). Steps $A$ and $B$ in the curve represent particles of approximately 8 and $16 \mathrm{~m} \mu$ in diameter respectively. $C$ indicates the distance through which Jasus lalandi haemocyanin was sedimented during the centrifugation. 
may be associated with increasing serological specificity. This observation is being studied and will be the subject of a further communication.

In the bluetongue-infected suckling mouse brains, as in the cases of the MEF strain of poliomyelitis and rabies viruses, complement fixation depends more on antigens of small particle size (soluble antigens) than on larger particles such as the viruses themselves. These can be sedimented at appropriate speeds by ultracentrifugation.

Because of the difficulties of standardizing the method of preparation of the crude saline antigens, the further repetition of these experiments was considered to be unwarranted.

It can be concluded, however, that the apparent non-specificity of the complement-fixation reaction in comparison with the neutralization tests depends largely on the presence of the soluble antigens which are of major significance in the former and insignificant in the latter. The soluble antigens of the bluetongue viruses would appear therefore to be similar.

It is fully realized that some of the strains of virus used for these experiments may, as a result of repeated passage in laboratory animals, have undergone significant changes since they were first isolated from sheep or bovines. This, together with differences in technique, may account for some of the differences of cross-immunity reported by Neitz (1948) and the neutralization tests recorded in this paper. Some of the differences are gross. The cross-immunity tests in sheep indicate a striking similarity between the strains Theiler and Bekker, which is in sharp contrast to their difference in mouse neutralization tests.

Strain differentiation for the purposes of vaccine manufacture is obviously best determined in sheep, and mouse neutralization tests can be regarded as confirming that significant differences do exist between the various strains of bluetongue virus. Complement-fixation tests cannot be relied upon for the determination of antigenic differences important in the identification of strains to be incorporated in a polyvalent vaccine. The comparative non-specificity of the complement-fixation tests probably points to the presence of identical or similar soluble antigens produced in the tissues in which the viruses are propagated. The ether- and acetone-extracted antigens in particular should prove of value in the preparation of antigens for the diagnosis of the disease by an in vitro method.

\section{SUMMARY}

Six strains of bluetongue virus were compared by cross complement-fixation tests performed on Perspex sheets according to the method of Fulton \& Dumbell using antigens derived from crude saline extracts, and acetone and ether extracts, of infected suckling mouse brains. Only minor differences were encountered with the former and no significant differences with the latter. The reasons for this are discussed.

In the neutralization tests important differences were demonstrated between strains.

There is evidence that the soluble antigen is composed of particles of varying 
size, that the smaller particles are responsible for the marked overlapping in the complement-fixation tests, and that increasing complexity associated with increasing particle size may be concerned with increasing serological specificity.

I am very grateful to Prof. M. van den Ende for his advice and encouragement in this work; to Dr A. Polson for his advice and help with the centrifugation experiments; to Dr R. A. Alexander for providing the strains; and to Mrs J. Hyland and Mr J. Rademen for their technical assistance.

The Virus Research Unit received additional grants from the Nkana-Kitwe and Chingola Poliomyelitis Research Funds.

\section{REFERENCES}

Alexander, R. A. (1947). Onderstepoort J. Vet. Sci. $22,7$.

Alexander, R. A. \& HaIG, D. A. (1951). Onderstepoort J. Vet. Sci. 25, 3.

Casals, J. (1947). J. Immunol. 56, 337.

Casals, J. (1949). Proc. Soc. exp. Biol., N.Y., 70, 339.

Fulton, F. \& Dumbell, K. R. (1949). J. gen. Microbiol. 3, 97.

KERR, J. A. (1952). J. Immunol. 68, 461.

Kraft, L. M. \& Melnick, J. L. (1950). J. exp. Med. 92, 483.

Mayer, M. M., Osler, A. G., Bier, O. G. \& Heidelberger, M. (1946). J. exp. Med. 84, 535.

NeITZ, W. O. (1948). Onderstepoort J. Vet. Sci. 23, 93.

Polson, A. \& Lrnder, A. M. (1953). Biochem. biophys. Acta, 11, 199.

Polson, A. \& Madsen, T. (1954). Biochem. biophys. Acta, 14, 366.

Reed, L. J. \& Muench, H. (1938). Amer. J. Hyg. 27, 493.

vaN DeN ENDE, M., Linder, A. \& KaschUla, V. R. (1954). J. Hyg., Camb., $52,155$.

van Den Ende, M., Turner, G. S., Selzer, G. \& Naude, W. du T. (1953). S. Afr. med.J. 27, 975.

(MS. received for publication 16. vזrI. 55) 